\title{
Prevent Osteoporosis: Catch the Silent Thief ${ }^{1}$
}

Linda B. Bobroff ${ }^{2}$

\section{Why the Concern?}

Osteoporosis has been called the "silent thief." It robs bone from women (and some men) with no outward signs. Eventually, even a minor stumble might

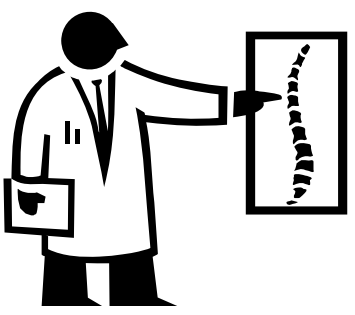
cause a hip fracture. Spine fractures can result in the stooped posture known as "dowager's hump."

Osteoporosis means porous bones-bones that have so many openings (pores) that they can crush or break without warning.

About 50 percent of women and 25 percent of men over age 50 will have a bone fracture caused by osteoporosis in their lifetimes. Many of these fractures, especially in the spine and hip, cause pain, disability, and loss of independence. About 24 percent of people aged 50 and over who have a hip fracture die in the year following the fracture.

In the United States, osteoporosis causes approximately $1 \frac{1}{2}$ million fractures per year, mostly in the hip, spine, and wrist. Medical costs of fractures, including nursing home care, are estimated to be $\$ 18$ billion per year. To that figure we must add these impacts:

- Loss of income

- Temporary loss of independence

- Loss of services and productivity

- Stress on family/caregivers
- Other health care costs

Of patients who fracture their hips, fewer than 50 percent recover "normal" function.

Osteoporosis is similar to high blood pressure in that it displays no symptoms until a complication occurs. There is no cure, so prevention is essential to combat this disease.

\section{Bone-A Mineral Warehouse}

Often bone is thought of as static and unchanging. Actually, it constantly turns over, with new bone formed and existing bone broken down. When

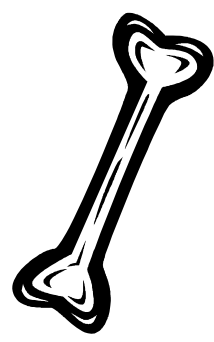
bone formation and breakdown is balanced, the amount of bone mass stays about the same.

During growth, more bone is formed than is lost. From the mid-thirties on, breakdown tends to exceed formation, and there is a slow, gradual loss of bone from then on.

Since bone loss is certain, the more people have to begin with, the more they will have as they get

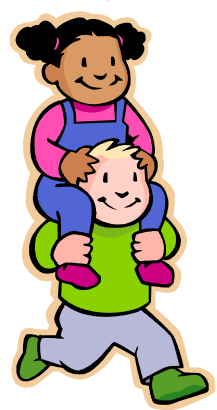
older. You can make choices early in life to help build bone mass before the loss begins. As you get older, you can slow down bone loss with positive lifestyle choices. Throughout life, diet and exercise are two things we all can control to reduce risk of osteoporosis.

1. This document is FCS8145, one of a series of the Department of Family, Youth and Community Sciences, Florida Cooperative Extension Service, Institute of Food and Agricultural Sciences, University of Florida. First published: 1989. Revised: April 2007. Please visit the EDIS Web site at http://edis.ifas.ufl.edu.

2. Linda B. Bobroff, Ph.D., RD, LD/N., professor, Department of Family, Youth, and Community Sciences, University of Florida, Gainesville, FL 32611

The Institute of Food and Agricultural Sciences (IFAS) is an Equal Opportunity Institution authorized to provide research, educational information and other services only to individuals and institutions that function with non-discrimination with respect to race, creed, color, religion, age, disability, sex, sexual orientation, marital status, national origin, political opinions or affiliations. For more information on obtaining other extension publications, contact your county Cooperative Extension service. U.S. Department of Agriculture, Cooperative Extension Service, University of Florida, IFAS, Florida A. \& M. University Cooperative Extension Program, and Boards of County Commissioners Cooperating. Larry Arrington, Dean. 


\section{Who Will Get Osteoporosis?}

The exact cause of osteoporosis is not known. It is known as a "multifactorial" disease. In other words, many factors contribute to the disease. Some of the risk factors for osteoporosis are "innate," or beyond a person's control. Others are lifestyle-related and can be controlled. People make decisions every day that can reduce the risk for developing osteoporosis.

Risk factors that cannot be controlled are sex, race, family history, menstrual status, body build, and certain medical conditions.

Women are much more likely to get osteoporosis than men. Black people are less likely to develop osteoporosis than whites or Asians. Those with a family history of the disease and people with a thin body build have a higher risk. Obesity seems to protect individuals against osteoporosis. This is due to estrogen production in fat tissue and to increased load on the bone.

Although obesity protects against osteoporosis, it is associated with increased risk for other conditions. Obese persons are more likely to have diabetes, cardiovascular disease, certain forms of cancer and other conditions.
In women, the rate of bone loss speeds up during menopause. After about age 65, the rate of loss slows down. Women who stop menstruating due to excessive exercise or from eating disorders also lose bone.

Several medical conditions increase the risk of osteoporosis. Persons with diabetes and thyroid disease and those taking certain medications are at high risk for this bone-robbing disease. (See Table 1.)

Even people who have many risk factors can decrease their risk of osteoporosis with lifestyle choices. These include getting enough calcium, vitamin $\mathrm{D}$, and weightbearing exercise, not smoking, and avoiding excess alcohol.

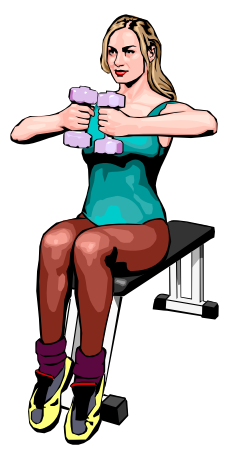

\section{Calcium for Building Bones}

Bone is constantly breaking down and rebuilding. Adequate calcium and other minerals are essential for rebuilding bone. For this reason, it's important to consume a diet with adequate calcium, vitamin $\mathrm{D}$, and other minerals that are important for bone health.

\begin{tabular}{|l|l|}
\hline Table 1: Risk Factors for Osteoporosis \\
\hline Innate & Lifestyle-related \\
\hline Older age & Too little vitamin D (from the diet or sun exposure) \\
\hline Female & Too little calcium in diet \\
\hline Caucasian or Asian & Too little exercise \\
\hline Family history & Nicotine use \\
\hline Menopause & Excessive alcohol use \\
\hline Hysterectomy & $\begin{array}{l}\text { Medications (steroids, anti-convulsants, antacids } \\
\text { with aluminum, thyroid extract) }\end{array}$ \\
\hline Amenorrhea* & \\
\hline Petite body build (weight under 127 pounds) & \\
\hline $\begin{array}{l}\text { Hormone or chemical imbalance (such as } \\
\text { diabetes or thyroid disease) }\end{array}$ & \\
\hline * Absence of menstrual period & \\
\hline
\end{tabular}


Bones and teeth contain 99 percent of the calcium in the body. The other one percent is found in the blood and other body fluids where it helps in blood clotting and nerve transmission. Calcium is stored in the bones and drawn upon when the daily intake is too low to meet the body's needs.

The current daily recommendation for calcium intake is 1,000 milligrams $(\mathrm{mg})$ for adult women age 19 to 50 and $1,200 \mathrm{mg}$ for women 51 and older. Teens 18 and younger need 1,300 $\mathrm{mg}$ of calcium a day.

\section{Getting Calcium from Foods}

The best way to get enough calcium is through the diet. Many foods are good sources of calcium. Including them in meals and snacks can help meet calcium needs. Table 2 shows the calcium content of some common foods.
Dairy foods are excellent sources of calcium. To keep intake of fat, saturated fat, and cholesterol low, choose low-fat and fat-free milk, yogurt, and cheese.

Other foods, such as leafy green vegetables, also are good sources of calcium. Choose broccoli, collards, turnip greens, mustard greens, cabbage, and kale.

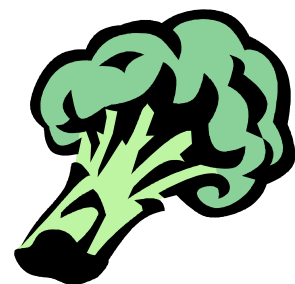
Canned salmon (including the mashed bones) and sardines are high in calcium too.

Oxalic acid in some green vegetables and phytic acid in whole-grain foods interfere with calcium absorption. Therefore, the calcium in whole grains and spinach, chard, and beet greens is less available than calcium from other food sources.

\section{Table 2. Calcium in Selected Foods}

\begin{tabular}{|l|c|l|c|}
\hline Food & $\begin{array}{c}\text { Calcium } \\
(\mathbf{m g})\end{array}$ & Food & $\begin{array}{c}\text { Calcium } \\
\text { (mg) }\end{array}$ \\
\hline Whole milk, 1 cup & 290 & Parmesan cheese, grated, 1 ounce & 390 \\
\hline Low-fat milk (1\%), 1 cup & 300 & $\begin{array}{l}\text { American cheese, (processed), } \\
\text { 1 ounce }\end{array}$ & 175 \\
\hline Fat-free milk, 1 cup & 300 & Creamed cottage cheese (1\%), 1 cup & 140 \\
\hline Nonfat dry milk, 1 Tbsp. & 60 & Ice cream (light), 1 cup & 180 \\
\hline Chocolate milk (1\%), 1 cup & 250 & Orange juice, fortified, 3/4 cup & $260-450$ \\
\hline Buttermilk (1\%), 1 cup & 285 & $\begin{array}{l}\text { Pink salmon, canned with bones, } \\
\text { 3 ounces }\end{array}$ & 180 \\
\hline Yogurt (low-fat), 1 cup plain & 450 & $\begin{array}{l}\text { Sardines with bones (drained), } \\
\text { 3 ounces }\end{array}$ & 325 \\
\hline Yogurt (low-fat), 1 cup fruit-flavored & 340 & Kale (cooked), 1 cup & 180 \\
\hline Yogurt (low-fat), 1 cup vanilla-flavored & 350 & Broccoli (cooked), 1 cup & 100 \\
\hline Swiss cheese, 1 ounce & 270 & Collard greens (cooked), 1 cup & 225 \\
\hline Cheddar cheese, 1 ounce & 200 & Turnip greens (cooked), 1 cup & 250 \\
\hline Mozzarella cheese, part skim, 1 ounce & 180 & Tofu (calcium fortified), 2 ounces & 280 \\
\hline Source: Food Processor SQL, Version 10.0. ESHA Research, Inc., 2006-07 & \\
\hline
\end{tabular}


Table 3 below provides examples of how to include calcium-rich foods in meals and snacks. People who have high calcium needs or avoid dairy foods may need to take a supplement.

\begin{tabular}{|c|c|c|}
\hline Meal & Food & $\begin{array}{l}\text { Calcium } \\
\text { (mg) }\end{array}$ \\
\hline \multicolumn{3}{|l|}{ DAY 1} \\
\hline Breakfast & $\begin{array}{l}1 \% \text { milk , } 3 / 4 \text { cup } \\
\text { Fortified cereal, } 1 \text { cup }\end{array}$ & 225 \\
\hline Lunch & $\begin{array}{l}\text { Whole milk, } 3 \text { Tbsp } \\
\text { (added to coffee) }\end{array}$ & 55 \\
\hline Snack & $\begin{array}{l}\text { Vanilla low-fat yogurt, } \\
1 \text { cup }\end{array}$ & 350 \\
\hline \multirow{2}{*}{ Dinner } & Cooked greens, $3 / 4$ cup & 175 \\
\hline & Fat-free milk, $3 / 4$ cup & 225 \\
\hline & TOTAL & 1030 \\
\hline \multicolumn{3}{|l|}{ DAY 2} \\
\hline Breakfast & $\begin{array}{l}\text { Waffles, fortified, } 2 \\
\text { Orange juice, fortified, } \\
3 / 4 \text { cup }\end{array}$ & $\begin{array}{l}225 \\
260\end{array}$ \\
\hline Lunch & $\begin{array}{l}\text { Swiss cheese, } 1 \text { ounce } \\
\text { (on sandwich) }\end{array}$ & 270 \\
\hline \multirow{2}{*}{ Dinner } & Broccoli spears, 1 cup & 100 \\
\hline & Fat-free milk, 1 cup & 225 \\
\hline & TOTAL & 1080 \\
\hline
\end{tabular}

\section{What About Supplements?}

Calcium supplements are available for those who do not get enough calcium from foods. The two main forms of calcium supplements are citrate and carbonate. The absorption is similar between the two. However, calcium citrate is better absorbed by people who have decreased stomach acid, such as older adults or people taking antacids.
It is a good idea to check with your doctor or pharmacist before taking any supplements. There are risks for some people who take high levels of calcium. Your doctor or pharmacist can also help you decide what type of calcium supplement is right for you.

For best absorption, take calcium supplements with food. It is also a good idea to consume calcium from food or supplements throughout the day rather than all at one time. The body can only absorb about $500 \mathrm{mg}$ of calcium at a time.

To be absorbed, calcium tablets must dissolve in the stomach. It is best to purchase your supplements from a reliable manufacturer to ensure you are getting a

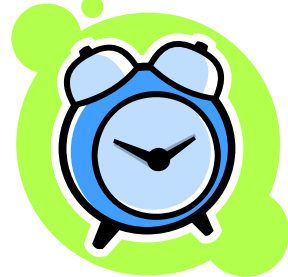
quality supplement. A USP (United States Pharmacopeia) symbol on the bottle means the supplement will dissolve and also will be free from lead.

Some foods naturally low in calcium, like orange juice, are available with added calcium. These fortified foods are an alternative for people who limit other calcium sources.

Nutrition labels list the calcium content of food. Note that the percent of Daily Value on the label is based on 1000 milligrams (see Table 4).

Table 4. Foods Supplemented with Calcium

\begin{tabular}{|l|c|c|}
\hline & $\begin{array}{c}\text { \% Daily } \\
\text { Value }\end{array}$ & $\begin{array}{c}\text { Calcium } \\
\text { (mg) }\end{array}$ \\
\hline $\begin{array}{l}\text { Cereal, calcium- } \\
\text { fortified, 1 cup }\end{array}$ & $10-100 \%$ & $100-1000$ \\
\hline $\begin{array}{l}\text { Orange juice, calcium- } \\
\text { fortified, 6 ounces }\end{array}$ & $26-45 \%$ & $260-450$ \\
\hline $\begin{array}{l}\text { Soy beverage, } \\
\text { calcium-fortified, } \\
8 \text { ounces }\end{array}$ & $8-50 \%$ & $80-500$ \\
\hline
\end{tabular}




\section{Vitamin D}

Vitamin D promotes calcium absorption. This vitamin is made in the skin after exposure to sunlight. It also is added to fortified milk and some other fortified foods.

The recommended intake for vitamin $\mathrm{D}$ is 5 micrograms $(\mu \mathrm{g})(200 \mathrm{IU})$ for those 19 to 50 years old, $10 \mu \mathrm{g}(400 \mathrm{IU})$ for those 51 to 70 and $15 \mu \mathrm{g}$ (600 IU) for persons over 70. Children

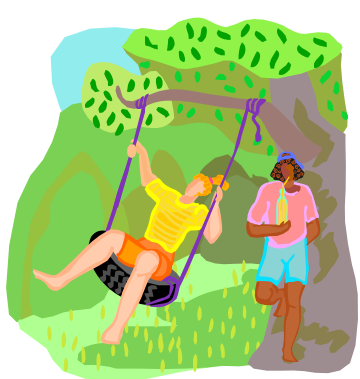
and adolescents should have $5 \mu \mathrm{g}$ of vitamin $\mathrm{D}$ per day. Spending 10 to 15 minutes in the sun each day (without sunscreen) and eating fortified foods will help meet vitamin $\mathrm{D}$ needs.

Recent research indicates that many people may be vitamin $\mathrm{D}$ deficient and recommended intakes may increase in the future. This is especially true for older adults, who are less efficient at making vitamin $\mathrm{D}$ from sun exposure.

Getting enough calcium and vitamin D helps build bone and decrease risk for osteoporosis. Eating a wide variety of foods from all food groups in recommended amounts will ensure consumption of other minerals that promote bone health. More information about nutrition and diet recommendations can be found at http://MyPyramid.gov.

Physical activity, including weight-bearing exercise, is the next lifestyle factor that promotes bone health.

\section{Move It or Lose It}

Exercise is important in preventing osteoporosis. The expression, "Move it or lose it," can apply to bones.
During body movement, muscles pull against bones. The resulting stress on the bone causes minerals (chiefly calcium) to be deposited in the bone. This makes the bone denser and stronger.

The best type of exercise for building bones is weight-bearing exercise. The exercise most often recommended is brisk walking. Strength training with free weights or machines also helps to build bones.

Sticking to an exercise program for the long term can be a challenge for some people. Choosing an enjoyable exercise plan is important. Walking

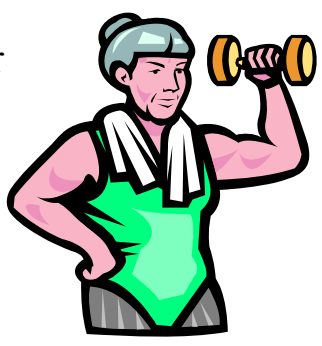
with a friend or walking in a pleasant park, for example, may help encourage an active lifestyle.

Some ideas for incorporating physical activity into the day are to:

- Walk during lunch and other breaks at work.

- Park the car in the back of parking lots at work and when shopping.

- Take the stairs instead of elevators or escalators when possible.

- Do some errands on foot.

- Walk to a co-worker's office instead of using e-mail to communicate.

- Relax with a favorite sport instead of in front of the television.

- When watching television, do calisthenics, or just walk around during the commercials.

It's important to choose activities that will not increase the risk of fracture from a fall or other injury. People who have not been active for awhile should start slowly; check with a doctor before beginning a new exercise program.

\section{Advice for Teens and Preteens}

Age is another significant factor in bone formation. Bone mass increases during growing periods, and peaks at about age 30 . It is especially important for teen and preteen girls to live a lifestyle that promotes bone health to help 
build bones for the predictable postmenopausal bone loss.

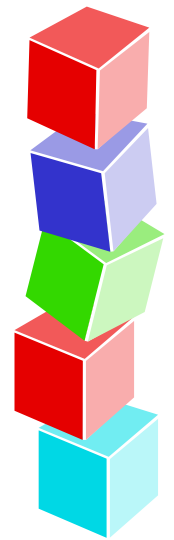

Because bone building requires calcium "building blocks," teens and preteens need to have an adequate calcium intake. This age group is likely to be diet conscious, and may avoid dairy foods thinking that they are "fattening." Teen and preteen girls should be encouraged to consume a variety of low-fat or fatfree calcium and vitamin D dietary sources. Eating a variety of fruits and vegetables will provide other needed minerals, such as magnesium that also support bone health.

Teens and preteens also should have opportunities for vigorous exercise every day, whether at school or in after school and weekend activities. Weight-bearing exercise will help build strong bones.

\section{Estrogen Therapy}

During the childbearing years, a woman's body produces the hormone estrogen. At menopause, the production drops. This drop in estrogen may contribute to bone loss. Hormone replacement therapy (HRT) provides relief for some women who have severe symptoms when going through menopause.

Estrogen is not recommended for all women, since it has several side effects, including increased risk of stroke and blood clots. HRT also may increase the risk of endometrial cancer. Estrogen combined with progestin lowers the risk of endometrial cancer, but when the two hormones are used together, menstrual bleeding resumes.

Estrogen/progestin therapy causes other side effects, including swelling, cramping, and breast tenderness. Health risks include increased risk of breast cancer, stroke, blood clots, and heart disease.
When considering estrogen or estrogen/ progestin therapy, it's important to discuss the risks and benefits with a doctor.

\section{Debating a Dietary Dilemma}

As we learn more about osteoporosis, there are more questions that need to be answered. Scientists still don't agree on appropriate treatments for osteoporosis. Prevention seems to be the best approach.

A healthful diet that includes getting enough calcium, vitamin $\mathrm{D}$, and other nutrients, exercising regularly, limiting alcohol intake, and not smoking are wise practices for

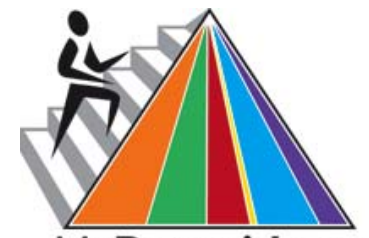
MyPyramid.gov STEPS TO A HEALTHIER YOU general health and can help prevent osteoporosis. Hormone replacement therapy for menopausal women is still controversial, due to the risks that may outweigh the benefits.

Another aspect of the dilemma is that dairy foods, the main sources of calcium in the American diet, are not consumed by many ethnic groups. This may be due to cultural preferences or to lactose intolerance. Nutrition education that is sensitive to cultural differences can help people make food selections that meet nutritional needs.

\section{Summary}

Osteoporosis is a serious and common disease that has many causes. Enjoying a healthy lifestyle that includes healthful food choices and physical activity can help people keep strong bones for a lifetime.

\section{Selected References}

Administration on Aging. Aging Internet Information Notes: Osteoporosis. Available at: http://www.aoa.gov/prof/notes/notes osteoporosis.asp. Accessed April 26, 2007. 
Bupta G, Aronow WS. Hormone replacement therapy - An analysis of efficacy based on evidence. Geriatrics. 57:18-20, 2002.

National Institutes of Health. Dietary Supplement Fact Sheet: Calcium. Available at: http://ods.od.nih.gov/factsheets/calcium.asp.

Accessed April 26, 2007.

National Institutes of Health. Menopausal Hormone Therapy Information. Available at: http://www.nih.gov/PHTindex.htm. Accessed April 26, 2007.

National Osteoporosis Foundation. Disease Statistics "Fast Facts.” Available at: http://www.nof.org/osteoporosis/diseasefacts. htm. Accessed April 26, 2007.
U.S. Department of Health and Human Services and the Surgeon General's Office. The 2004 Surgeon General's Report on Bone Health and Osteoporosis. Available at:

http://www.hhs.gov/surgeongeneral/library/bone health/content.html. Accessed April 26, 2007.

U.S. Food and Drug Administration. Boning Up on Osteoporosis, 2004. Available at:

http://www.fda.gov/fdac/features/796 bone. html. Accessed April 26, 2007.

Wu F., et al. Prospective 10-year study of the determinants of bone density and bone loss in normal post-menopausal women, including the effect of hormone replacement therapy. Clin Endocrinol, 56:703-11, 2002.

\section{Calcium-Containing Recipes}

\section{Old-Fashioned Baked Rice Pudding $^{\mathrm{a}}$}

1 quart fat-free milk

$1 / 3$ cup uncooked rice (not converted)

$1 / 4$ cup sugar

$1 / 2$ teaspoon salt

$1 / 4$ cup raisins (softened in hot water if needed)

Ground nutmeg

Preheat oven to 300 degrees. Combine milk, rice, sugar and salt in a lightly buttered twoquart casserole. Bake uncovered for two hours, stirring every 30 minutes. Add raisins during the last 30 minutes of baking, and stir.

Upon standing the rice will absorb the rest of the milk. Sprinkle with nutmeg. Serve warm or chilled with additional milk, if desired. Makes four servings.

Each serving provides approximately: Calories: 200

Fat: Less than 1 gram Calcium: 300 milligrams

${ }^{\mathrm{a}}$ Reprinted with permission, National Dairy Board

\section{Fresh Fruits with Orange Custard Sauce}

$1 \frac{1}{2}$ cups $1 \%$ milk (or use fat-free)

2 tablespoons sugar

1 tablespoon cornstarch

$1 \frac{1}{2}$ teaspoons grated orange peel

1 egg yolk

2 cups mixed fresh fruit cut in bite-sized pieces (e.g., pears, peaches, apples, grapes, pineapple, etc.)

In a small saucepan combine milk, sugar, cornstarch, orange peel, and egg yolk. Cook and stir over medium heat until mixture comes to a boil. Boil for one minute, stirring constantly. Serve warm or cold over cut fruits. Makes two servings.

Each serving provides approximately:

Calories: 270

Fat: $\quad 5$ grams

Calcium: 250 milligrams 


\section{Morning Shake}

1 cup $1 \%$ milk (or use fat-free)

1 cup sliced frozen banana

3 tablespoons frozen orange juice concentrate

$1 / 2$ teaspoon pure vanilla extract

In the container of an electric blender place milk, banana, orange juice and vanilla. Cover and blend until smooth. Serve at once. Makes two servings.

Each serving provides approximately:

Calories: 150

Fat: $\quad 1.4$ grams

Calcium: 160 milligrams

\section{Yogurt Popsicles (great for kids!)}

1 cup plain low-fat or fat-free yogurt

1 banana, sliced

1 teaspoon vanilla

1 cup fruit juice or fruit chunks

Blend ingredients together and pour into small paper cups. Freeze. Place a plastic spoon or popsicle stick in each cup when yogurt mixture is half frozen. To serve, turn cup upside-down and run hot water over it until the popsicle slips out. Keep the cups to use as a holder. Makes four to five small popsicles.

Each popsicle provides approximately: Calories: $\quad 90$

Fat: 1 gram Calcium: 120 milligrams

\section{Italian Rice Bake}

$2 / 3$ cup uncooked rice (or 2 cups cooked rice)

$11 / 3$ cups water (if using uncooked rice)

1 onion, chopped

1 tablespoon margarine

1 6-ounce can tomato paste (no salt added) and

1 can water

$1 / 2$ teaspoon garlic powder

1 teaspoon sugar

Dash pepper

$1 / 2$ teaspoon whole thyme

$1 / 2$ teaspoon dried oregano, crushed

1 teaspoon parsley flakes

$1 \frac{1}{2}$ cups low-fat cottage cheese

$1 / 2$ cup grated part-skim mozzarella cheese

Cook rice in water. In a skillet, sauté onion in the margarine. Add tomato paste, water, garlic powder, sugar, pepper, thyme, oregano, and parsley to onion mixture.

Combine cottage cheese and rice.

Put $1 / 3$ of rice mixture in non-stick sprayed casserole dish. Top with $1 / 3$ of tomato sauce. Continue to alternate layers, ending with tomato sauce. Top with grated cheese. Bake at 325 degrees for 30 minutes, until hot and bubbly. Makes six servings.

Each serving provides approximately. Calories: 200

Fat: $\quad 5$ grams

Calcium: 130 milligrams

\footnotetext{
${ }^{\mathrm{b}}$ Reprinted with permission from Cooking ala Heart by Linda Hachfeld, MPH, RD and B. Eykyn, MS: (c) 2006. Published by Appletree Press, available by calling (800) 322-5679 or visiting the website, www.appletreepress.com
} 


\section{Cauliflower Walnut Casserole}

Because of the cheese and nuts, this is more a vegetable entrée than a side dish. Serve with a salad, French bread, and a fruit dessert. For variety, substitute broccoli or cabbage for the cauliflower.

1 medium head cauliflower, broken into florets 1 cup plain low-fat yogurt

1 cup shredded reduced-fat Cheddar cheese

1 tablespoon flour

2 teaspoons low-sodium, chicken flavored bouillon granules

1 teaspoon dry mustard

$1 / 3$ cup chopped walnuts

$1 / 3$ cup fine dry bread crumbs

1 tablespoon margarine

1 teaspoon dried marjoram, crushed

In a medium sauce pan bring water to a boil. Add cauliflower, reduce heat, and simmer 15 minutes. Drain.

Mix yogurt, cheese, flour, bouillon granules, and mustard. Place cauliflower in $10 \times 6$ inch or 8 inch square baking dish and spoon yogurt mixture over cauliflower.

Mix together walnuts, bread crumbs, margarine, and marjoram; sprinkle over cauliflower and sauce. Bake at 400 degrees about 20 minutes, until casserole is bubbly. Makes four entrée servings.

Each serving provides approximately: Calories: 240

Fat: $\quad 12$ grams

Calcium: 300 milligrams

\footnotetext{
${ }^{\mathrm{b}}$ Reprinted with permission from Cooking ala Heart by Linda Hachfeld, MPH, RD and B. Eykyn, MS: (c) 2006. Published by Appletree Press, available by calling (800) 322-5679 or visiting the website, www.appletreepress.com
}

\section{Broccoli Quiche}

1 pound fresh broccoli, cut into florets (or use frozen broccoli)

2 eggs, beaten

$1 / 4$ cup unbleached flour

2 cups low-fat ( $1 \%$ ) cottage cheese

2 ounces part-skim mozzarella cheese, grated

$1 / 4$ cup fresh parsley, finely chopped

1 tablespoon lemon juice (fresh is best)

$1 / 2$ teaspoon dried basil

$1 / 4$ teaspoon dried oregano

$1 / 4$ teaspoon salt (optional)

$1 / 4$ teaspoon pepper

Preheat oven to 350 degrees. Cut fresh broccoli into florets; peel and slice stems. In a saucepan or steamer cook broccoli with a small amount of water over medium heat until tender-crisp; drain and chop coarsely.

Beat eggs in a bowl. Add flour and mix until well blended. Add remaining ingredients; mix well. Spray a 9 x 9-inch baking pan with vegetable cooking spray and pour in the broccoli mixture. Bake 35 to 40 minutes at 350 degrees. Cool for two to three minutes. Cut into squares. Makes four servings.

Each serving provides approximately:

Calories: 250

Fat: $\quad 7$ grams

Calcium: 250 milligrams 


\section{Tomato Raita}

1 medium cucumber, peeled

$1 / 2$ teaspoon salt (optional)

2 medium tomatoes, cored, cut into $1 / 2$-inch

cubes and drained

1 tablespoon onion, finely chopped

1 cup low-fat plain yogurt

$1 / 4$ cup fresh parsley, chopped

2 tablespoons fresh cilantro (coriander),

chopped

1 teaspoon cumin (or to taste)

Cut cucumber in half lengthwise and remove seeds. Cut into thin crosswise slices and place in a bowl. Sprinkle with salt. Let stand for 40 minutes. Rinse and drain, squeezing cucumber slightly to remove excess moisture. Add tomatoes and onion. In a bowl combine yogurt, parsley, cilantro, and cumin; mix well. Pour over vegetables; mix well. Cover. Chill until serving time.

Makes four servings.

Each serving provides approximately: Calories: 60

Fat: 1 gram

Calcium: 130 milligrams

\section{Mousse a la Banana}

2 tablespoons low-fat (1\%) milk

4 teaspoons sugar

1 teaspoon vanilla

1 medium banana, cut in quarters

1 cup plain, low-fat yogurt

$8 \frac{1}{4}$-inch banana slices

Place milk, sugar, vanilla, and banana in blender and process 15 seconds at high speed until smooth. Pour mixture into a small bowl; fold in yogurt. Chill. Spoon into four dessert dishes; garnish each with two banana slices just before serving. Makes four servings.

Each serving provides approximately:

Calories: $\quad 95$

Fat: $\quad 1$ gram

Calcium: 125 milligrams

\section{Creamy Potatoes}

1 pound potatoes (red skinned potatoes work well)

1 cup evaporated fat-free milk

2 teaspoons reduced-fat tub margarine

2 tablespoons chopped fresh chives (or 2

teaspoons dried)

$1 / 2$ teaspoon salt

$1 / 4$ teaspoon white pepper (or to taste)

3 tablespoons water

Wash and peel potatoes; cut into small pieces. Boil the potatoes 20 to 30 minutes or until they can be easily pierced with a fork. Mix remaining ingredients in a large bowl. Drain potatoes and whip with the milk mixture. Makes six servings.

Each serving provides approximately:

Calories: 100

Fat: $\quad 1$ gram

Calcium: 125 milligrams 